AARP INTERNATIONAL THE JOURNAL

VOLUME $11-2018$ EDITION

AARP

Real Possibilities

Plan Well, Live Well: AARP Eyes Financial Resilience for All

By Ramsey Alwin 


\title{
Plan Well, Live Well: AARP Eyes Financial Resilience for All
}

\author{
By Ramsey Alwin
}

W orries over inadequate savings are keeping Americans in their 50 s and older (50+) from fully enjoying their longevity, according to 2017 Gallup polling. AARP is aware of this reality, and it's tackling the issue.

We have deployed a multi-pronged strategy to provide tools that will enable more individuals to get on track for financial resilience and security. Our strategy focuses on financial planning, building savings, increasing work opportunities, and protecting the most vulnerable savers from scammers. Our bottom-line goal is to enable each of our 38 million members to choose the financial futures they want and share more fulfilling years with family and friends.

\section{Concerning Numbers}

The numbers show that we as a nation should be addressing this issue. Across all socio-economic groups, Americans $50+$ have not saved enough for the future:

- Approximately 41 percent of US households headed by people ages 55-64 - or over 9 million households - have no retirement assets.

- For US workers ages 45-54 with savings, almost half (48 percent) have less than $\$ 50,000$ in assets, not including their house or any defined benefit pension plan (which are relatively uncommon these days).

Thus, Americans are worried about, or even overwhelmed by, their inadequate savings and savings rates:

- Not having enough money for retirement surpasses all other financial concerns among Americans 50+, according to a 2017 Gallup poll.
- More than two-thirds (69 percent) of Americans are forced to focus on current financial needs (causing them to put off setting aside funds for future needs), according to an AARP survey. They often find it difficult to save for retirement even though they recognize the importance of financial planning.

- Half of Americans told AARP they don't have enough money left to save after paying bills.

- Nearly half of American private sector employees (55 million people) do not have access to workplace savings plans.

Thus, AARP has prioritized building savings through work and financial planning. Our efforts are holistic, reaching into multiple arenas.

\section{Building Savings}

Every day AARP challenges policymakers and leaders from different sectors to dismantle barriers to financial security and shore up earnings protections. Thanks to the efforts of AARP and other experts and advocates working on the issue, recently implemented state legislation has increased the number of employers that offer retirement savings plans. In addition, given the evidence-based link between a lack of emergency savings and the inability to save for retirement (or even the need to dip into retirement savings), AARP has begun to explore strategies that foster greater short-term emergency savings, connecting it to the long-term retirement savings problem.

On the individual level, Americans can Ace their Retirement, a critical 2017 message built through AARP's part- nership with the Ad Council to move Americans to save more. Inspired by ideas from leading global behavioral economists, AARP designed and tested solutions that nudge the $50+$ to build savings, protect it, and plan financially.

\section{Planning for the Future}

With institutions promising less with respect to retirement security, millions face an uncertain future that includes potentially outliving their resources. Further, Americans are increasingly entrepreneurs - actors in the gig economy - and they feel primary responsibility for their own financial health. AARP is responding by working with financial incubators, start-ups, and venture capitalists to help people better manage money throughout their lifetime.

Meanwhile, with aging the possibility of dementia increases, which in turn increases the risk of financial exploitation by scammers. AARP recognizes the growing need for supplemental financial management assistance. We partner with financial institutions and arm consumers and corporations with powerful financial protections.

\section{Continuing to Work}

Beyond savings and planning, other trends may offer opportunities that can work in older Americans' financial favor. As indicated through AARP's Living 100 initiative, which is examining the opportunities and broader implications of ever-increasing life expectancy in many countries, a longer life can mean extended careers. At a recent Living 100 event in Washington DC, demographer James Vaupel, founding Director of the Max Planck Institute for Demographic Research, summed it up: "If people work longer, they don't have to save as much. If you are healthy enough to work, work is good for you." 


\section{Concerning Numbers}

Across all socio-economic groups, Americans 50+ have not saved enough for the future:

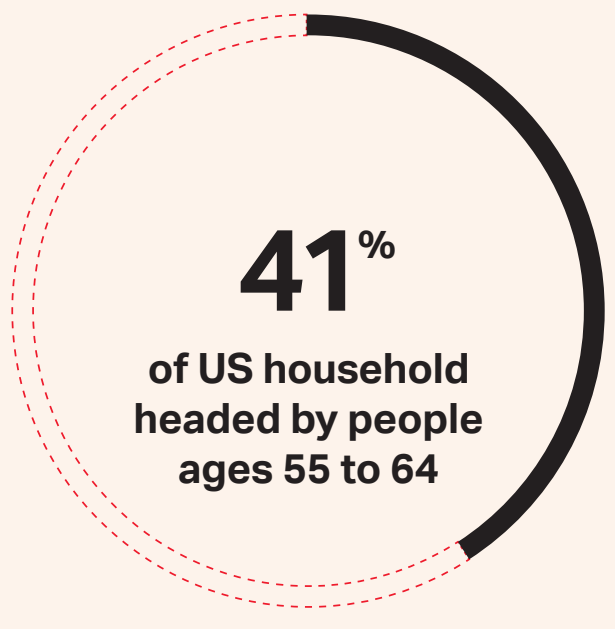

No Retirement Assets

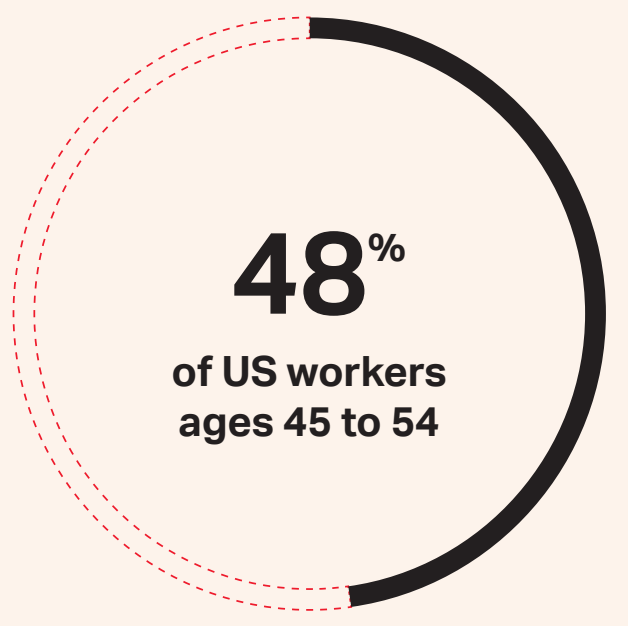

\section{Have less than US \$50k in Assets}

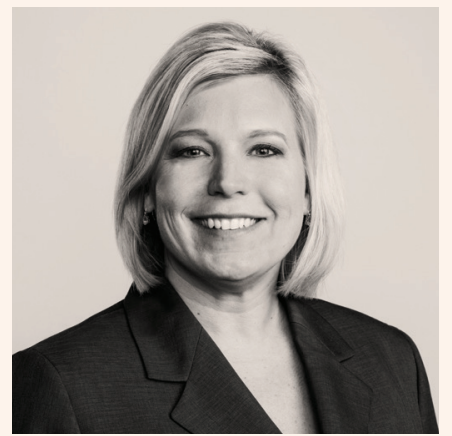

Ramsey Alwin DIRECTOR FINANCIAL RESILIENCE, THOUGHT LEADERSHIP, AARP
Most of us will need to reskill to work longer as retirement ages rise. Within five years, 35 percent of the workforce will be $50+$. AARP is helping employers support inclusivity, combat ageism and recognize that older workers bring talent, experience, and added value (e.g., being highly engaged) - all of which can outweigh any concerns over labor costs. Knowing that labor shortages drive the greatest opportunities for workers $50+$ AARP also guides members on how to market their unique attributes.

The AARP Work \& Jobs website's (www.aarp.org/work) unique resources and personal resilience tools enable members to find appropriate and fulfilling work as they lead longer lives.
Just some of the features include: a list of companies that value experienced workers, research showing that diversity leads to better business outcomes, and tips for job seekers and career changers.

\section{Our Approach}

AARP's multi-pronged strategy - comprising policy, programs, products and free educational information - continues to prepare consumers to secure more financial freedom as they get older. With thought leadership and innovation, AARP makes more accessible the wealth that empowers us to be our best selves in good health. 
AARP International engages global stakeholders to spark solutions that strengthen communities, protect the vulnerable and enable people around the world to pursue their goals and dreams. Working with governments, civil society and the private sector, we are focused on enhancing the quality of life for people as they age. We serve as the global voice for AARP, a social change organization with a membership of more than 37 million.

THE JOURNAL ONLINE

aarpinternational.org/journal

AARP INTERNATIONAL ONLINE

aarpinternational.org

FACEBOOK

facebook.com/aarpintl

TWITTER

@aarpintl

CONTACT

AARP International

601 E Street, NW

Washington, DC 20049

United States

T +1 2024342398

E international@aarp.org

AARP International: The Journal is a publication of AARP. The views expressed herein do not necessarily represent policies of AARP and should not be construed as endorsements. The mention of a product or service herein is solely for information to our readers and may not be used for any commercial purpose. AARP, which was established in 1958, is a nonprofit, nonpartisan organization with tens of millions of members ages 50 and older. State offices are located in all 50 states, the District of Columbia, Puerto Rico, and the Virgin Islands.

January 2018

()2018, AARP

Reprinting with permission only. 